\title{
Computed Tomography evaluation of maxillofacial injuries
}

\author{
V Natraj Prasad, Ashish Khanal \\ Department of Radiodiagnosis, College of Medical Sciences- Teaching Hospital, Bharatpur, Nepal
}

\section{Correspondence \\ Dr. Ashish Khanal \\ Department of Radiodiagnosis, \\ College of Medical Sciences- \\ Teaching Hospital, Bharatpur, Nepal}

\section{Email:}

ashishmaiden@gmail.com

DOI: http://dx.doi.org/10.3126/ jemsn.v12i4.16372

Article received: Aug $5^{\text {th }} 2016$ Article accepted: Sept $2^{\text {nd }} 2016$

\begin{abstract}
Background \& Objectives: The maxillofacial region, a complex anatomical structure, can be evaluated by conventional (plain) films, Tomography, Multidetector Computed Tomography, Three-Dimensional Computed Tomography, Orthopantomogram and Magnetic Resonance Imaging. The study was conducted with objective of describing various forms of maxillofacial injuries, imaging features of different types of maxillofacial fractures and the advantage of using Three- Dimensional Computed Tomography reconstructed image. Materials \& Methods: A hospital based cross-sectional study was conducted among 50 patients during April 2014 to September 2016 using Toshiba Aquilion Prime 160 slice Multi Detector Computed Tomography scanner. Results: The maxillofacial fractures were significantly higher in male population $(88 \%)$ than female population (12\%). Road traffic accidents were the most common cause of injury others being physical assault and fall from height. It was most common in 31-40 years (26\%) and 21-30 (24\%) years age group. Maxillary sinus was the commonest fracture (36\%) followed by nasal bone and zygomatic bone (30\%), mandible and orbital bones $(28 \%)$. Soft tissue swelling was the commonest associated finding. Three dimensional images (3 D) compared to the axial scans missed some fractures. However, the extension of the complex fracture lines and degree of displacement were more accurately assessed. Complex fractures found were Le fort $(6 \%)$ and naso-orbito-ethmoid $(4 \%)$ fractures. Conclusion: The proper evaluation of complex anatomy of the facial bones requires Multidetector Computed Tomography which offers excellent spatial resolution enabling multiplanar reformations and three dimensional reconstructions for enhanced diagnostic accuracy and surgical planning.

Key words: 3D-CT, Computed tomography, Fractures, Maxillofacial, Road traffic accidents
\end{abstract}

Citation: Prasad VN, Khanal A. Computed Tomography evaluation of maxillofacial injuries. JCMS Nepal. 2016;12(4):131-6.

\section{INTRODUCTION}

Maxillofacial injuries are increasingly common among trauma patients occurring either in isolation or with other serious injuries. Despite the increasing safety precautions in driving, motor vehicle accidents account for majority of these injuries particularly involving the facial bones, orbits and adjacent soft tissue structures. Fall injuries, physical assault and sports injury account for minor proportion of these patients. ${ }^{1}$ In Nepal alone, road traffic accidents (RTA) account for the highest mortality rate reaching approximately 15 to 20 times than that of developed nations. According to national statistics of Nepal, more than 11,000 people were injured due to RTA in 2009 to 2010 and are increasing year by year. There are various disparities in reported incidences of such trauma. Young males with orbito-zygomatic complex fractures are frequently involved. ${ }^{2}$ Although many of the principles of detection and repair are basic, the evolution of imaging technology and therapeutic strategies has led to improved patient outcomes.

The maxillofacial region is one of the most complex anatomical structures of the human body and the radiographic imaging of this region becomes further difficult in traumatic patients. Imaging modalities used in the evaluation of the traumatic maxillofacial region include conventional (plain) films, 
Multidetector Computed Tomography (MDCT), Three-Dimensional Computed Tomography (3 D$\mathrm{CT}$ ), Orthopantomogram (OPG) and Magnetic Resonance Imaging (MRI). ${ }^{3}$

Plain radiography is the initial imaging modality in trauma patients; but due to inadequate information its significance in maxillofacial trauma has declined in assessing the severity of the injury. MDCT is the imaging modality of choice and is the most accurate investigation in evaluating the patients of maxillofacial trauma. MDCT helps in detecting the exact site, number and extent of fractures, displacement of fragments and soft tissue injuries in much less time. ${ }^{4}$ It is an important imaging modality in diagnosing the mandibular fractures. ${ }^{5,6}$ The spatial resolution of MDCT is excellent, which enables Multiplanar Reformations (MPR) and 3-D reconstructions allowing better diagnostic accuracy and surgical planning and provides excellent information about fracture comminution and displacement. ${ }^{7}$ Involvement multiple planes in complex fractures can be assessed which aids in the surgical management. ${ }^{8}$ In MPR and 3-D reconstructions there is no additional burden of radiation exposure.

Facial fractures are classified into mid-face and mandibular fractures. There may be isolated bone fractures or complex facial fractures. Complex facial fractures commonly include Naso-OrbitoEthmoid and Le fort fractures. The use of the Le Fort classification, although sometimes inadequate, is a succinct way of communicating and summarizing the major fracture planes that exist by evaluating the pterygoid processes and the distinctive components of each type of Le Fort fracture. $^{9}$

This study describes the features of various maxillofacial injuries evaluated by MDCT and 3DCT imaging. The aim of this study was to describe various forms of maxillofacial injuries with the help of CT scan, imaging features of different types of fractures in patients with maxillofacial injuries and advantage of using 3D $\mathrm{CT}$ reconstructed image over axial $\mathrm{CT}$ images in patients with maxillofacial injuries.

\section{MATERIALS AND METHODS}

The study was carried out in the Department of Radiodiagnosis, College of Medical ScienceTeaching Hospital, Bharatpur, after the approval of proposal by subject committee and Ethical Committee. It was a hospital based cross sectional study done for a period of two years from 2014 to
2016 in 50 patients who were referred to the department of Radiodiagnosis with maxillofacial injuries using TOSHIBA Aquilion Prime 160 slice CT scanner.

MDCT with volumetric acquisition was done in axial planes from upper border of frontal sinus to chin using standard CT protocol. From axial images thin sections $(1.25 \mathrm{~mm})$ were made through inbuilt software followed by multiplanar reconstructions (MPR) in coronal and sagittal planes along with 3D reconstruction. Collected data was analyzed using SPSS (Statistical Package for the Social Sciences) 20. Descriptive analysis was done to generate frequency tables for various types of maxillofacial injuries.

\section{RESULTS}

Maxillary sinus wall fracture was the commonest fracture in this study accounting for 36\% (18) of cases (Figure 1). The second most common fractures were nasal bone and zygomatic bone accounting for $30 \%$ (15) cases each. The next most common fractures were of mandible and orbital bones accounting for $28 \%$ (14) of cases. Frontal bone $(16 \%)$, temporal bone $(12 \%)$, parietal bone $(6 \%)$, occipital bone (4\%) and sphenoid bone (2\%) were also present. Pterygoid plate fractures were present in $6 \%$ cases.

The frequency of maxillofacial fractures was higher in males accounting for $88 \%$ of cases whereas in females, it accounted for only $12 \%$ of cases with male: female ratio of 7.3:1.

Zygomatic bone was the commonest fracture in females $(6 \%)$. In males, maxilla was the most common fractured bone $(32 \%)$.

RTA was the commonest cause of injury in males (72\%) others being physical assault (10\%) and fall from height $(6 \%)$. In females RTA accounted for all the cases of maxillofacial injuries $(12 \%)$. Overall RTA was the commonest mode of injury accounting for $84 \%$ of cases followed by fall from height $10 \%$ and physical assault $3 \%$.

Maxilla and maxillary sinus fractures were the commonest fractures in this study accounting for $36 \%$ of cases. The mode of injury was road traffic accident. Combined anterior and medial wall fractures were the most common injury pattern observed (50\%). (Table 2)

Nasal bone fracture was present in $26 \%$ of cases. Majority of cases were from RTA (22\%) followed by physical assault $(2 \%)$ and fall from height $(2 \%)$.Bony nasal septum fracture was present in $4 \%$ cases which was associated with nasal bone 
Table 1: Frequency of fractures by age group

\begin{tabular}{|lcc|}
\hline Age group (yrs) & Frequency & $\%$ \\
\hline $1-10$ & 3 & 6 \\
\hline $11-20$ & 8 & 16 \\
\hline $21-30$ & 12 & 24 \\
\hline $31-40$ & 13 & 26 \\
\hline $41-50$ & 7 & 14 \\
\hline $51-60$ & 5 & 10 \\
\hline $71-80$ & 1 & 2 \\
\hline $81-90$ & 1 & 2 \\
\hline Total & 50 & 100 \\
\hline
\end{tabular}

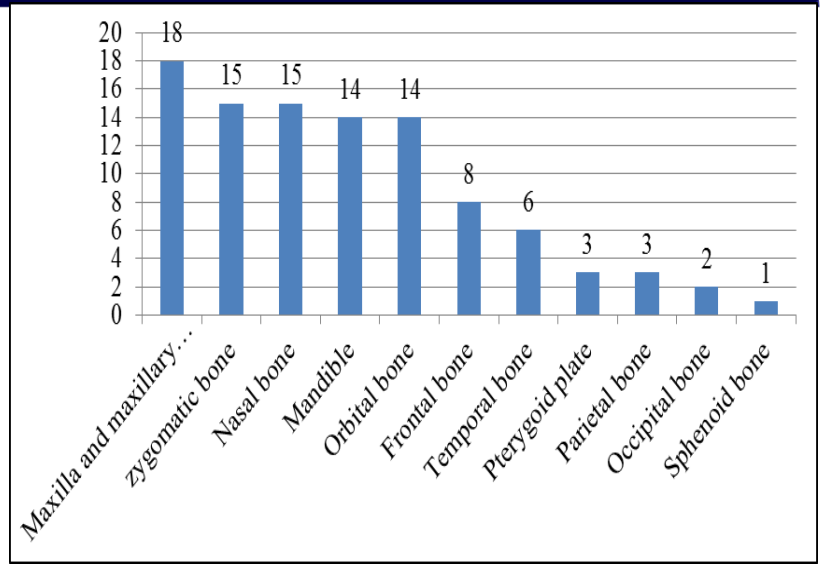

Figure 1: Frequency of different maxillofacial fractures

Table 2: Frequency of maxilla and maxillary sinus fractures

\begin{tabular}{|c|c|c|c|}
\hline Maxillary sinus fracture & Frequency & $\begin{array}{c}\text { Percentage } \\
\text { of total }\end{array}$ & $\begin{array}{l}\text { Percentage of total } \\
\text { maxillary fractures }\end{array}$ \\
\hline Anterior wall & 2 & 4 & 11.1 \\
\hline Anterior, medial lateral wall & 9 & 18 & 50 \\
\hline $\begin{array}{l}\text { Anterior, medial wall, alveolar } \\
\text { process }\end{array}$ & 1 & 2 & 5.6 \\
\hline Anterior, lateral wall & 1 & 2 & 5.6 \\
\hline Anterior wall, alveolar process & 2 & 4 & 11.1 \\
\hline Medial wall, alveolar process & 1 & 2 & 5.6 \\
\hline Lateral wall & 2 & 4 & 11.1 \\
\hline Total & 18 & 36 & 100 \\
\hline $\begin{array}{l}\text { fractures. } \\
\text { Orbital bone fracture was present } \\
\text { RTA was the mode of injury. Lat } \\
\text { most common fracture }(50 \%) \text { fol } \\
\text { wall }(28.6 \%) \text { and roof }(14.3 \%) \text {. } \\
\text { and medial wall fracture accou } \\
\text { suggestive of complex blow out fre } \\
\text { Frontal bone fractures accounted } \\
\text { cases. Out of which } 62.5 \% \text { (n= } \\
\text { fracture, } 25 \% \text { were type } 2 \text { fracture } \\
\text { type } 3 \text { fracture. Type } 4 \text { and Type } \\
\text { not found in this study. Sphenoid } \\
\text { present in only } 2 \% \text { of cases whic } \\
\text { wing of sphenoid bone. Road tra } \\
\text { the cause of injury. } \\
\text { Temporal bone fracture was pre } \\
\text { cases. Squamous portion was th } \\
\text { fractured part (10\%) followed by } \\
\text { (2\%). RTA was the mode of tempo } \\
\text { Soft tissue swelling was the comn } \\
\text { findings. It was followed by } \\
\text { commonly maxillary sinus. }\end{array}$ & $\begin{array}{l}28 \% \text { of cases. } \\
\text { al wall was the } \\
\text { wed by medial } \\
\text { mbined inferior } \\
\text { ed for } 1 \text { case } \\
\text { ture. } \\
16 \% \text { of total } \\
\text { were Type } 1 \\
\text { and } 12.5 \% \text { was } \\
\text { fractures were } \\
\text { ng fracture was } \\
\text { was in greater } \\
\text { accident was } \\
\text { mt in } 12 \% \text { of } \\
\text { most common } \\
\text { petrous portion } \\
l \text { bone injury. } \\
\text { nest associated } \\
\text { nus collection } \\
\text { sociated other }\end{array}$ & \multicolumn{2}{|c|}{$\begin{array}{l}\text { serious injuries were pneumocephalus, contusion, } \\
\text { SAH, SDH, EDH, Subdural hygroma and scalp } \\
\text { hematoma. } \\
\text { Among the fractures missed by 3D image compared } \\
\text { to the axial scans, maxillary sinus medial wall } \\
\text { fracture was the commonest one }(16 \%) \text {, followed } \\
\text { by pterygoid plate fracture }(4 \%) \text {, frontal sinus } \\
\text { posterior wall }(2 \%) \text {, nasal bone }(2 \%) \text { and sphenoid } \\
\text { bone }(2 \%) \text {. } \\
\text { Among total cases } 4 \% \text { had NOE fractures. Le fort } \\
\text { fractures were present in } 6 \% \text { of total patients with } \\
\text { Le Fort I, Le Fort II and Le Fort III patterns } \\
\text { accounting for } 2 \% \text { each. }\end{array}$} \\
\hline
\end{tabular}


In our study RTA accounted for majority of cases of maxillofacial injuries (84\%) with other causes being physical assault (10\%) and fall from height $(6 \%)$. The location of the hospital midway along the busiest highway of the country could explain for increased number of RTA cases presenting to the hospital. The injuries were found to be overwhelmingly common in male population ( $88 \%$ of cases) compared to females (12\%) with male: female ratio of 7.3:1. The maxillofacial injuries were most common in $31-40$ years and $21-30$ years age group accounting for $26 \%$ and $24 \%$ of total cases respectively.

The facial fractures of all injuries are found to be common in young males. ${ }^{11}$ Although the frequent mode of facial injuries in developing countries in studies by Adekeye et al., ${ }^{12}$ Bochlogyros et al. ${ }^{13}$ and Haug et al. ${ }^{14}$ was road traffic accidents, various results in developed countries show high incidence of assault as the commonest cause of maxillofacial injury. ${ }^{15}$ Because of social, cultural, and environmental factors the causes of maxillofacial fractures vary. ${ }^{16}$

In a five year prospective study by Motamedi et al. ${ }^{17}$ and six month prospective study by Kamulegeya et al., ${ }^{18}$ the most common fracture found was mandibular fracture, however, maxilla and maxillary sinus was the most common middle third facial region fracture. Isolated posterior maxillary wall fractures are rare. They are commonly associated with ipsilateral mandibular fractures and may involve TMJ. ${ }^{19}$ In our study maxilla and maxillary sinus fractures were the commonest fractures accounting for $36 \%$ of cases. The mode of injury was RTA. Combined anterior and medial wall fractures were the most common injury pattern observed (50\%)

Ogura et al. $^{20}$ characterized the locations of different mandibular fractures using MDCT. Mandibular fractures were classified into median, paramedian, angle, condylar and coronoid process types. The percentage of multiple mandibular fractures was $80.9 \%$ median type, $74.3 \%$ paramedian type, $52.9 \%$ angle type and $60.9 \%$ condylar type. The data showed a significant relationship between multiple fractures and the median type, paramedian type and condylar type in decreasing order. In our study, mandibular fractures accounted for $28 \%$ (14) of total cases. Combined body and ramus fractures was the most common pattern $(28.6 \%)$.

In present study, orbital bone fracture was present in $28 \%$ of cases. RTA was the mode of injury. Lateral wall was the most common fracture $(50 \%)$ followed by medial wall $(28.6 \%)$ and roof $(14.3 \%)$. Combined inferior and medial wall fracture accounted for one case suggestive of complex blow out fracture. This occurs due to force of impact transmitted by the orbital rim to the orbital floor causing it to shatter usually in the middle third portion. The inferior orbital and eyeball usually remains undamaged. The presence of an air-fluid level or the fracture of the maxillary sinus is common.

Obuekewe et al. ${ }^{21}$ found that road traffic accidents was responsible for most zygomatic complex fractures. $76.1 \%$ were males and $23.9 \%$ females. The most common site of fracture in decreasing order were that of the zygomatic bone $(88 \%)$ zygomatic arch $(8.2 \%)$, and both the zygomatic bone and arch (3\%). In a metaanalysis of maxillofacial trauma by Ravindran et al., ${ }^{22}$ the most prevalent midface injury was in the zygomatic region $(209,36.4 \%)$, followed by orbital $(102,17.8 \%)$, Le Fort I (18, 3.1\%), Le Fort II $(43,7.5 \%)$ and Le Fort III $(10,1.7 \%)$.

Nasal bone fracture is the commonest isolated bone fractures.23 In our study, nasal bone fracture was present in $26 \%$ of cases. Bony nasal septum fracture was present in $4 \%$ cases.

Among the fractures missed by 3D image compared to the axial scans in our study, maxillary sinus medial wall fracture was the commonest one $(16 \%)$, followed by pterygoid plate fracture $(4 \%)$, frontal sinus posterior wall $(2 \%)$, nasal bone $(2 \%)$ and sphenoid bone $(2 \%)$ fractures.

In the assessment of frontal bone fracture, detection and displacements were seen better on $3 \mathrm{D}$ images in more percentage of patients. However, its extension, especially into posterior wall of sinus or roof of orbit was not adequately visualized due to the overlap of the bony anterior wall of the sinus restricting visualization. 3D images were found to be similar for the detection and description of extent in most patients with zygomatic bone fractures. In the assessment of displacement, it was found to be superior to axial images in most patients.

Kaur et al. ${ }^{24}$ evaluated mid facial fractures in 100 patients using 3D CT. It was shown that 3D reconstruction helped in preoperative analysis and surgical planning. It was valuable in case of severe facial injury enabling a clear perception of 
extent of major fracture lines and resulting displacement of fragments.

Many studies have noted that 3D reconstructed images are helpful in the evaluation of fracture comminution, displaced components, and complex fractures involving multiple planes. The extent of comminuted fractures is better demonstrated on the 3D-CT, where the size, shape, and displacement of individual fragments are clearly revealed. $^{25-28}$ The combination of multislice CT and 3D volume rendering technique allowed several improvements in imaging interpretation.

Absence of free paranasal sinus fluid (clear sinus sign) in facial CT is a highly reliable criterion for excluding fractures involving the paranasal sinus walls. $^{29}$

\section{CONCLUSION}

The complex anatomy of the facial bones requires multiplanar imaging techniques for a proper evaluation. The main purpose of diagnostic imaging is to detect and localize the exact number, site of facial fractures and soft tissue injuries. MDCT offers excellent spatial resolution, which in turn enables exquisite multiplanar reformations, and 3-D reconstructions, allowing enhanced diagnostic accuracy and surgical planning.

\section{REFERENCES}

1. Rowe LD, Miller E, Brandt-Zawadzki M. Computed tomography in maxillofacial trauma. Laryngoscope. 1981;91(5):745-57. DOI: 10.1288/00005537-19810500000007. PMID:7231023.

2. Yadav SK, Mandal BK, Karn A, Sah AK. Maxillofacial trauma with head injuries at a tertiary care hospital in Chitwan, Nepal: clinical, medico-legal, and critical care concerns. Turk J Med Sci. 2012;42(Sup. 2):1505-12.

3. Laine FJ, Conway WF, Laskin DM. Radiology of maxillofacial trauma. Curr Probl Diagn Radiol. 1993;22 (4):145-88. DOI: 10.1016/0363-0188(93)90019-P.

4. Salonen EM, Koivikko MP, Koskinen SK. Acute facial trauma in falling accidents: MDCT analysis of 500 patients. Emerg Radiol. 2008;15(4):241-7. DOI: 10.1007/s10140008-0717-2. PMID:18481126.

5. Schuknecht B, Graetz K. Radiologic assessment of maxillofacial, mandibular, and skull base trauma. Eur Radiol 2005;15(3):560-8. 10.1007/s00330-004-2631-7. PMID:15662492.

6. Chotkowski GC. Symphysis and parasymphysis fractures. Atlas Oral Maxillofac Surg Clin North Am. 1997;5(1):2759. PMID:11905344.

7. Som PM, Curtin HD. Head and neck imaging.5th ed. St. Louis, Mo: Mosby;2002. PMCID:PMC153815.

8. Saigal K, Winokur RS, Finden S. Use of three-dimensional computerized tomography reconstruction in complex facial trauma. Facial Plast Surg. 2005;21(3):214-20. 10.1055/s2005-922862. PMID:16307402.

9. Rhea JT, Novelline RA. How to simplify the CT diagnosis of Le Fort fractures. AJR Am J Roentgenol. 2005;184 (5):1700-5. 10.2214/ajr.184.5.01841700. PMID:15855142.
10. Sojot AJ, Meisami T, Sandor GK, Clokie CM. The epidemiology of mandibular fractures treated at the Toronto general hospital: A review of 246 cases. J Can Dent Assoc. 2001;67(11):640-4. PMID:11841744.

11. Kieser J, Stephenson S, Liston PN, Tong DC, Langley JD. Serious facial fractures in New Zealand from 1979 to 1998. Int J Oral Maxillofac Surg. 2002;31(2):206-9. 10.1054/ ijom.2002.0208. PMID:12102421.

12. Adekeye EO. The pattern of fractures of the facial skeleton in Kaduna, Nigeria. A survey of 1,447 cases. Oral Surg Oral Med Oral Pathol. 1980; 49(6):491-5. DOI: 10.1016/0030-4220(80)90068-7.

13. Bochlogyros PN. A retrospective study of 1,521 mandibular fractures. J Oral Maxillofac Surg. 1985;43 (8):597-599. DOI: 10.1016/0278-2391(85)90127-2.

14. Haug RH, Prather J, Indresano AT. An epidemiologic survey of facial fractures and concomitant injuries. J Oral Maxillofac Surg.1990;48(9):926-32. DOI: 10.1016/02782391(90)90004-L.

15. Rix L, Stevenson AR, Punnia-Moorthy A. An analysis of 80 cases of mandibular fractures treated with miniplate osteosynthesis. Int J Oral Maxillofac Surg. 1991;20(6):33741. DOI: 10.1016/S0901-5027(05)80261-9.

16. Khan AA. A retrospective study of injuries to the maxillofacial skeleton in Harare, Zimbabwe. $\mathrm{Br} \mathrm{J}$ Oral Maxillofac Surg. 1988;26(5):435-9. DOI: 10.1016/02664356(88)90098-8.

17. Motamedi MH. An assessment of maxillofacial fractures: a 5-year study of 237 patients. J Oral Maxillofac Surg. 2003;61(1):61-4. DOI: $\quad 10.1053$ /joms.2003.50049. PMID:12524610.

18. Kamulegeya A, Lakor F, Kabenge K. Oral maxillofacial fractures seen at a Ugandan tertiary hospital: a six-month prospective study. Clinics (Sao Paulo). 2009;64(9):843-8. DOI:

$10.1590 / \mathrm{S} 1807-59322009000900004$. PMID:19759877.

19. Simonds JS, Whitlow CT, Chen MY. Isolated fractures of the posterior maxillary sinus: CT appearance and proposed mechanism. AJNR Am J Neuroradiol. 2011;32(3):468-70. DOI: 10.3174/ajnr.A2337. PMID:21292798.

20. Ogura I, Kaneda T, Mori S, Sekiya k, Ogawa H. Characterization of mandibular fractures using 64-slice multidetector CT. Dentomaxillofac Radiol. 2012;41(5):392 -5. DOI: $10.1259 / \mathrm{dmfr} / 67127210$. PMID:22282503.

21. Obuekwe O, Owotade F, Osaiyuwu O. Etiology and pattern of zygomatic complex fractures: a retrospective study. J Natl Med Assoc. 2005;97(7):992-6. PMID:16080669.

22. Ravindran V, Ravindran Nair KS. Metaanalysis of Maxillofacial Trauma in the Northern Districts of Kerala: One Year Prospective Study. J Maxillofac Oral Surg. 2011;10(4):321-7. DOI: 10.1007/s12663-011-0264-3. PMID:23204748.

23. Baek HJ, Kim DW, Ryu JH, Lee YJ. Identification of Nasal Bone Fractures on Conventional Radiography and Facial CT: Comparison of the Diagnostic Accuracy in Different Imaging Modalities and Analysis of Interobserver Reliability. Iran J Radiol. 2013;10(3):140-7. DOI: 10.5812/ iranjradiol.6353. PMID:24348599.

24. Kaur J, Chopra R. Three dimensional ct reconstruction for the evaluation and surgical planning of mid face fractures: a 100 case study. J Maxillofac Oral Surg. 2010;9(4):323-8. DOI: 10.1007/s12663-010-0137-1. PMID:22190818.

25. Buitrago-Tellez CH, Schilli W, Bohnert M, Alt K. A comprehensive classification of craniofacial fractures: postmortem and clinical studies with two- and threedimensional computed tomography. Injury. 2002;33(8):651 -68. DOI: 10.1016/S0020-1383(02)00119-5.

26. Ohkawa M. The role of three-dimensional computed tomography in the management of maxillofacial bone fractures. Acta Medica Okayama. 1997; 51(4):219-225. PMID:9284970.

27. Cavalcanti MG, Haller JW, Vannier MW. Threedimensional computed tomography landmark measurement 
in craniofacial surgical planning: experimental validation in vitro. J Oral Maxillofac Surg. 1999;57(6):690-4. DOI: 10.1016/S0278-2391(99)90434-2.

28. Alder ME, Deahl ST, Matteson SR. Clinical usefulness of two-dimensional reformatted and three-dimensionally rendered computerized tomographic images: literature review and a survey of surgeons' opinions. J Oral Maxillofac Surg. 1995;53(4):375-86. DOI: 10.1016/02782391(95)90707-6.

29. Lambert DM, Mirvis SE, Shanmuganathan K. Computed tomography exclusion of osseous paranasal sinus injury in blunt trauma patients: the "clear sinus" sign. J Oral Maxillofac Surg. 1997;55(11):1207-10. DOI: 10.1016/ S0278-2391(97)90167-1. 